\title{
GINÁSTICA PARA TODOS \\ NO RIO GRANDE DO SUL: \\ DESAFIOS E PERSPECTIVAS
}

GIMNASIA PARA TODOS

EN RIO GRANDE DO SUL:

RETOS Y PERSPECTIVAS

GYMNASTICS FOR ALL

IN RIO GRANDE DO SUL:

CHALLENGES AND PERSPECTIVES

\author{
Annelise Link ${ }^{1,}$ \\ Danielle Mantovani ${ }^{1}$, \\ Michele Viviene Carbinatto ${ }^{1}$
}

\begin{abstract}
RESUMO
Introdução: O desenvolvimento esportivo se relaciona com diversos fatores, como exemplo, a atuação do técnico e políticas públicas. Este último perpassa tanto a promulgação de leis e estatutos para o esporte, como a organização e gestão de instituições promotora daquele. Objetivo: $\mathrm{O}$ foco de nosso estudo é elencar os desafios e perspectivas dos gestores da federação de ginástica do Rio Grande do Sul no que se refere o progresso da Ginástica para Todos (GPT). Metodologia: Foram entrevistados o presidente e a diretora-técnica da GPT da respectiva federação. Como coleta, utilizou-se da entrevista semiestruturada, gravada e transcrita na íntegra e analisada por meio da Análise de Conteúdo. Resultados: Foi possível detectarmos duas categorias principais: desafios para ampliar a GPT no estado (compreensão da GPT; carga de trabalho; cultura ao alto rendimento) e perspectivas e direcionamentos futuros da gestão com a modalidade (parcerias com universidades; fortalecimento de festivais já organizados). Conclusão: Percebe-se que o estado já realiza ação que se aproxima da GPT (como o festival anual), no entanto as demandas e interesses nas ginásticas artística e rítmica se sobressaem. A interlocução com a universidade coincide com as pesquisas atuais na GPT para seu crescimento no país.
\end{abstract}

PALAVRAS-CHAVES: Ginástica. Gestão esportiva. Federação. Política pública.

\begin{abstract}
Introduction: Sports development depends on several factors, as the coach performance and public policy, which contains laws promulgation and sport statutes, such as organizing and management of those who promote the sports. Objective: The focus of the study is to present the challenges and perspectives of the Gymnastics Federation of Rio Grande do Sul/Brasil managers regarding the progress of Gymnastics for All (GfA). Methodology: Were interviewed both the GFA president and technical director of GfA from the respective federation. As a collection for database, were used semi-structured interviews, recorded and fully transcribed and analyzed using content analysis. Results: It was possible to detect two main categories: challenges to expand the GfA in the state (GfA understanding; workload; the high performance culture) and the sport's prospects and future management directions (partnerships with universities, strengthening festivals already in place). Conclusion: It is evident that the state already performs action that approaches the GfA (such as the annual festival), however the demands and interests in artistic and rhythmic gymnastics prevail. The dialogue with the
\end{abstract}

${ }^{1}$ Universidade de São Paulo - USP, São Paulo - Brasil

Contato: anny.link93@gmail.com

Submetido em: 26 jun. 2016 Acesso em: 15 jul. 2016

\begin{tabular}{|l|l|l}
\hline (C) Conexões & Campinas, SP & v. 14 \\
\hline
\end{tabular}

p. $25-46$

out./dez. 2016

ISSN 1983-9030 
university correlate with the current research in GfA for growth of this gymnastics in the country.

KEYWORDS: Gymnastics. Sports management. Federation. Public policy.

\section{RESUMEN}

Introducción: El desarrollo deportivo esta relacionado con varios factores, como la actuación del entrenador y las políticas públicas, las cuales, incluyen tanto la promulgación de leyes y estatutos para el deporte, como la organización y gestión de instituciones que las promueven. Objetivo: El estudio busca hacer una lista de los desafíos y perspectivas de los gerentes de la Federación de Gimnasia del Rio Grande del Sur con respecto al progreso de la Gimnasia para Todos (GPT). Metodología: Se entrevistó el presidente y la directora técnica del GPT de la respectiva Federación. Como recolección de datos, se utilizó entrevistas semiestructuradas, grabadas y transcritas textualmente y analizadas mediante análisis de contenido. Resultados: Fue posible detectar dos categorías principales: desafíos para ampliar la GPT en el estado (comprensión del GPT; carga de trabajo; cultura del alto rendimiento) y las perspectivas y direcciones futuras de la gestión de la modalidad (asociaciones con universidades, fortalecimiento de los festivales existentes). Conclusión: Aunque la Provincia haga acciones de aproximación del GPT (como el festival anual), las demandas e intereses por la gimnasia artística y rítmica se destacan. La interlocución con la universidad coincide con la investigación actual en GPT para el crecimiento de este deporte en el país.

PALABRAS CLAVE: Gimnasia. Gestión deportiva. Federación. Política pública. 


\section{INTRODUÇÃO}

É evidente que o esporte tornou-se condição indispensável no cotidiano da sociedade e as demandas dos seus promotores ampliaram-se consideravelmente, ${ }^{1-2}$ dentre os quais, o da gestão esportiva. Esta consiste na organização sistemática de atividades físicas ou esportivas e é feita por entidades responsáveis tanto pelos esportes de alto rendimento quanto pelos eventos de caráter participativo que visam à promoção de lazer e saúde da população. ${ }^{3}$

Sistematizar as estruturas organizacionais do esporte em um país não garante o sucesso no pódio, mas pesquisadores afirmam que aquelas podem interferir em bons resultados e serem analisadas em três níveis de influências, quais sejam:
a. macro: fatores socioeconômicos e culturais;
b. meso: fatores que podem ser influenciados por políticas esportivas; e,
c. micro: fatores particulares de cada atleta. ${ }^{4-6}$

Em se tratando da ginástica brasileira, a organização dirigente específica no âmbito nãogovernamental e nível federal é a Confederação Brasileira de Ginástica- CBG, que tem o encargo de dirigir, difundir, promover, organizar e aperfeiçoar as modalidades ligadas ao seu campo de atuação. Sua diretoria é composta pela diretoria de gestão (presidente e vicepresidente), conselho fiscal e os comitês técnicos de cada uma das modalidades (artística feminina, artística masculina, rítmica, aeróbica, acrobática, trampolim e ginástica para todos). ${ }^{7}$

Além disso, a CBG é composta por 24 Federações Estaduais de Ginástica, que atuam a nível municipal e estadual ${ }^{7}$ e são responsáveis pela promoção do esporte, o que torna fundamental a atuação destas organizações para garantir o progresso através de ações que promovam o fomento da ginástica no estado de sua abrangência. ${ }^{7}$

Seria óbvio pensarmos que todas as federações acionariam suas ações em prol do desenvolvimento de todas as modalidades abarcadas pela CBG, mas não é isso que acontece. A exemplo, na ginástica para todos, apenas oito federações são votantes e atuantes na Assembleia Geral da entidade, dentre elas a Federação de Ginástica do Rio Grande do Sul. 
Visto que compreender a gestão esportiva em uma determinada situação - como a ginástica para todos no RS- pode indicar caminhos para melhorias no âmbito de um esporte, bem como ampliar o conhecimento sobre processos de gestão na ginástica no Brasil - ainda insuficiente ${ }^{4,8}$ o presente trabalho intenta apresentar as percepções de dois dirigentes da modalidade acerca da sua expansão e efetivação no estado.

\section{OBJETIVOS}

O atual trabalho tem como finalidade compreender e apresentar a percepção do presidente da federação e da diretora técnica da Ginástica para Todos (GPT) do Rio Grande do Sul sobre a modalidade Ginástica para Todos. Pretende-se obter um panorama dos dirigentes acerca do contexto atual e direcionamentos futuros preteridos na modalidade.

\section{METODOLOGIA}

Pautada no método de pesquisa qualitativa, realizaram-se entrevistas com perguntas abertas e roteiro semiestruturado, que foram gravadas e transcritas na íntegra. Para a análise dos dados, utilizamos a técnica da Análise de Conteúdo 9 que dentre seus diversos domínios de aplicação, para este trabalho utilizou-se o cunho linguístico oral e comunicativo dual (de diálogo). A análise de conteúdo focalizou-se na modalidade temática que compreendeu três etapas:

a. Pré-análise: fase de transcrição das entrevistas realizadas, com surgimento de possíveis hipóteses a serem discutidas posteriormente;

b. Exploração do material: fase de codificação dos dados, com inicial seleção de informações e dados mais relevantes; e

c. Categorização: organização das informações em categorias que, por sua vez, organizam-se em Unidade de Registro (Temas recorrentes dentre os dados coletados) e Unidade de Contexto (Uma seleção de discursos coletados, que confirmam as unidades de registro).

Como critério de inclusão, foram considerados os gestores que diretamente trabalham com a modalidade de GPT na Federação de Ginástica do Rio Grande do Sul. Dois sujeitos atendiam 
ao critério: o presidente e a diretora técnica de GPT da respectiva federação. Informamos que não há um comitê técnico de GPT na modalidade em questão, o que restringiu nossos sujeitos. Devido aos discursos estarem estreitamente relacionados com a função dos sujeitos, os mesmos estão devidamente identificados como "Presidente" e "Diretora".

\section{REFFERENCIAL TEÓRICO}

Estudos sobre gestão esportiva são consideravelmente recentes, não apenas a nível nacional, ${ }^{10-12}$ mas também internacional. ${ }^{13-15}$ É comum detectarmos pesquisas na área que aludem ao funcionamento de programas esportivos pautados no modelo teórico intitulado SPLISS (Sports Policy Factors Leading to International Sporting Success), cuja intenção é avaliar fatores que influenciam o desenvolvimento esportivo por influência de políticas públicas, ${ }^{16-17}$ dentre eles análises sobre a atuação de organizações governamentais e/ou nãogovernamentais no esporte.

Em nosso país, a estrutura esportiva subdivide-se desde o nível federal até municipal, e pode ser apresentada pelo organograma a seguir:

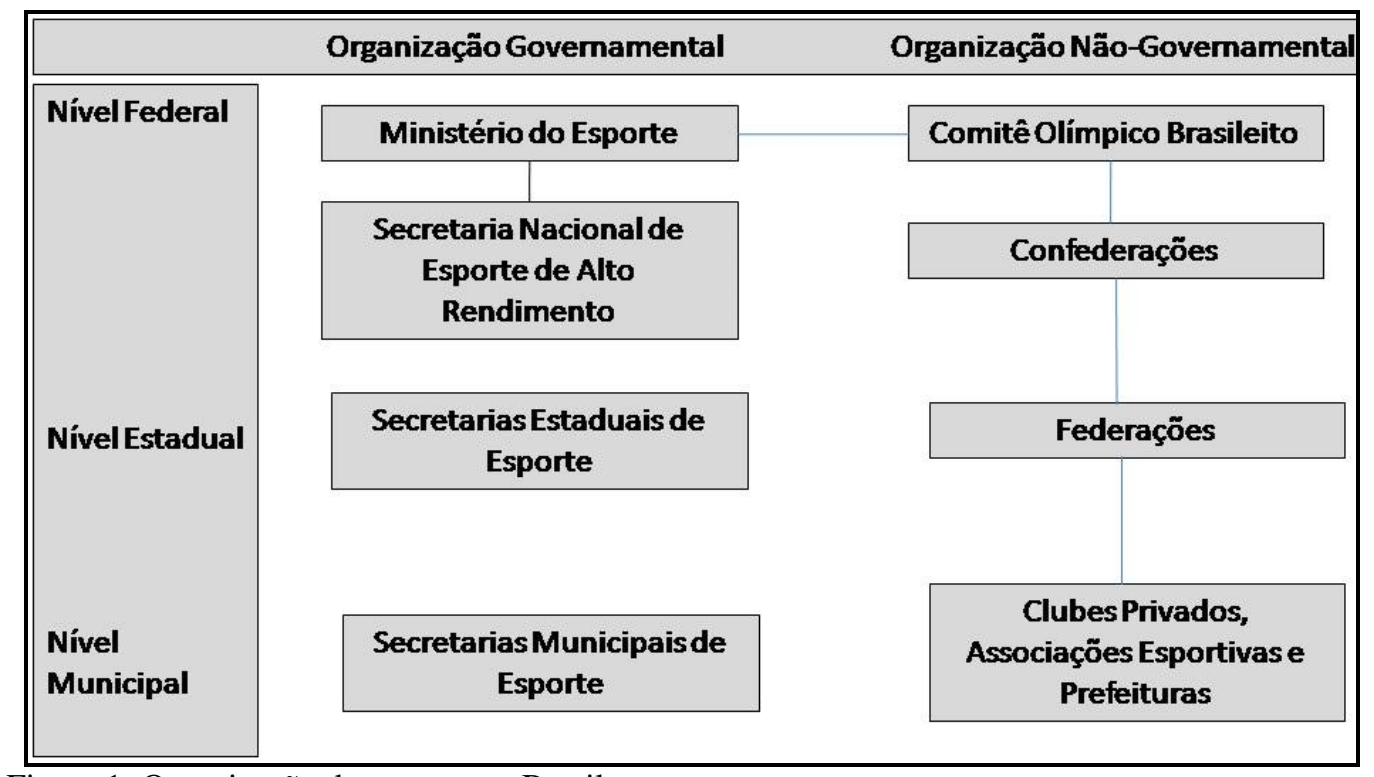

Figura 1: Organização do esporte no Brasil.

Fonte: MEIRA; BASTOS. ${ }^{36}$

Nota-se, portanto, que é possível analisar, sistematizar e discutir ações em gestão em diferentes esferas e também nas suas diferentes modalidades. No caso da Confederação

\begin{tabular}{|l|l|l|l|l|l|l}
\hline CC Conexões & Campinas, SP & v. 14 & n. 4 & p. 25-46 & out./dez. 2016 & ISSN 1983-9030 \\
\hline
\end{tabular}


Brasileira de Ginástica, uma das modalidades envoltas pelo estatuto e regulamento da entidade é a Ginástica para Todos.

A Ginástica para Todos (GPT) tem como principal característica o caráter não-competitivo e a promoção do lazer por meio de sua prática. A GPT apresenta fundamentos das atividades gímnicas aliados ao estímulo da criatividade e individualidade, manifestações corporais e culturais, tornando irrestrito o público participante. ${ }^{7,18-20}$

A GPT é modalidade ginástica que permite a multiplicidade das possibilidades de expressão, universalidade de gestos e facilidade de incorporação de processos formativos e educacionais. ${ }^{21}$ Ela é preconizada pelos fundamentos ginásticos (saltar, apoiar, suspender, equilibrar-se, deslocar-se e rotacionar-se) em conjunto com materiais/ equipamentos diversos (ex. Oficiais da competição - paralelas e trampolim; oficiais não-competição- bola de pilates e o step; adaptados- galão de água, bambu e construídos (placas de madeiras). ${ }^{22}$

Normalmente, o produto final do trabalho com a GPT se dá por meio de coreografias, que permitem alusão a diferentes tipos de manifestações e elementos da cultura corporal, como o folclore, jogos, danças e etc. Ainda tem como objetivo proporcionar o bem-estar e promover o lazer de seus participantes, sendo coletivo, mas respeitando as diferenças individuais, uma vez que não há limitações ou impedimentos a sua prática. ${ }^{18,23}$

Outra característica importante da GPT é a não competitividade. O foco principal desta modalidade é a busca e resgate do divertimento gímnico, ajudando no desenvolvimento da criatividade e ludicidade. ${ }^{19}$ A espontaneidade e oportunidade de criação, surgidas no andamento dessas atividades gímnicas é responsável por gerar momentos de lazer e liberdade de expressão corporal. ${ }^{18}$

Apesar de considerar a história corporal dos praticantes, a GPT também busca o desenvolvimento de novas habilidades motoras. A presença de desafios, experiências e oportunidades de superação devem contribuir para o pleno desenvolvimento do praticante, sempre respeitando seus limites. Mais do que o desenvolvimento motor, há na prática da GPT o intercâmbio de cultura, inclusão e socialização. ${ }^{24}$

De acordo com a Confederação Brasileira de Ginástica, ${ }^{7}$ os principais objetivos da GPT são:

\begin{tabular}{l|l|l|l|l|l|l}
\hline (C) Conexões & Campinas, SP & v. 14 & n. 4 & p. 25-46 & out./dez. 2016 & ISSN 1983-9030 \\
\hline
\end{tabular}


a. Oportunizar a participação do maior número de pessoas em atividades físicas de lazer fundamentadas nas atividades gímnicas;

b. Integrar várias possibilidades de manifestações corporais às atividades gímnicas;

c. Oportunizar a superação individual e coletiva, sem parâmetros comparativos com os outros;

d. Oportunizar o intercâmbio sociocultural entre os participantes;

e. Manter e desenvolver o bem-estar dos praticantes;

f. Oportunizar a valorização do trabalho coletivo, sem deixar de valorizar a individualidade neste contexto.

\section{RESULTADOS E DISCUSSÃO}

A Análise de Conteúdo ${ }^{9}$ aplicada aos dados coletados revelaram duas categorias para discussão:

a. Os desafios da GPT no RS, com as sub-categorias: valorização e entendimento efetivo da GPT; carga de trabalho dos dirigentes; contexto cultural do estado;

b. As perspectivas da GPT no RS: ampliar o Festival de GPT; melhorar as parcerias com as universidades e escolas.

Na Tabela 1, destacamos o perfil dos sujeitos entrevistados.

Tabela 1 - Perfil dos gestores entrevistados

\begin{tabular}{ccc}
\hline Característica & Presidente & Diretora de GPT \\
\hline Sexo & Masculino & Feminino \\
\hline Idade & 45 anos & 36 anos \\
\hline $\begin{array}{c}\text { Formação } \\
\text { Tempo de Experiência na } \\
\text { função }\end{array}$ & Doutor & Superior Completo \\
Ocupação Principal & 8 anos & 4 anos \\
Vida Esportiva & Técnico esportivo & Técnico esportivo \\
\hline Fonte: FIGUEIRÔA; MAZZEI; BASTOS ${ }^{4}$ & & Ginástica Artística \\
\hline
\end{tabular}




\section{DESAFIOS}

Valorização e compreensão sobre GPT

A GPT se apresenta por inúmeras facetas de grande valor sociocultural. A inclusão de pessoas com deficiência, idosos, crianças, pessoas de diferentes faixas etárias, etnias e etc, além do respeito por suas limitações, mas buscando a superação, são as características que mostram a real importância desta modalidade. Desta forma, é de extremo valor e relevância a inserção da mesma no estado, uma vez que irá permitir que um público até hoje extremamente restrito a algumas atividades tenha a oportunidade de experimentar algo novo, criativo e que promove o crescimento pessoal, o desenvolvimento das habilidades motoras e a comunicação social.

Levantou-se o conhecimento sobre a GPT pelos representantes gaúchos e seu entendimento sobre a mesma. Ambos os dirigentes são advindos da ginástica de competição, principalmente da ginástica artística, sendo que a diretora técnica, ex-atleta da GA teve sua primeira experiência com GPT ao participar de apresentações livres em finais de anos: “(...) $a$ gente fazia apresentação de finais de ano e aquilo começou a me motivar a falar com o João (presidente da federação gaúcha), porque a gente nunca tinha tido GPT aqui no Rio Grande do Sul, aí eu falei a João 'vamos fazer um festival, vamos introduzir, todo mundo pode participar' e isso que me motivou a entrar na GPT."

Apesar de ainda não tratar com propriedade e clareza sobre a modalidade, a diretora técnica compreende suas características principais, quais sejam: a ludicidade que permeia a prática, a inclusão de todos e a abrangência de movimentos "você pode fazer tudo o que você quiser, tudo o que mexe com o corpo é ginástica geral entendeu? (...) Na Gymnastrada que eu fui tinha idosos, crianças, todo mundo fazendo e todo mundo feliz. Então eu brinco que a ginástica geral é a ginástica para ser feliz (...)" e, inclusive, mostrou-se disposta para fazer capacitação e formação continuada no assunto.

O presidente da federação gaúcha teve seu primeiro contato com a GPT ao se tornar gestor. Segundo ele, nos primeiros anos de seu ciclo como dirigente, trabalhou somente com as ginásticas alocadas nos Jogos Olímpicos, sendo que a GPT começou a ser inserida no contexto gaúcho somente sem seu segundo ciclo como presidente: "Na realidade, quando eu entrei na federação, na verdade nos 3 primeiros anos eu só trabalhei com 3 modalidades,

\begin{tabular}{l|l|l|l|l|l|l}
\hline (C) Conexões & Campinas, SP & v. 14 & n. 4 & p. 25-46 & out./dez. 2016 & ISSN 1983-9030 \\
\hline
\end{tabular}


que eram artística, rítmica e de trampolim. Aí no quarto ano entrou a aeróbica e no 5 ano, no segundo ciclo, começou a se pensar na GPT."

Acreditamos que melhorar a compreensão da abrangência da GPT pelos gestores possa ampliar as suas possibilidades de ação, afinal, os ambientes de ginásticas não precisam (e nem devem!) estar abertos apenas para a detecção, seleção e promoção de atletas para o alto rendimento.

É preciso ampliar parcerias, por exemplo, com a secretaria de educação, demonstrando a GPT e o seu viés formativo $;{ }^{25-26}$ além da secretaria de saúde e suas possibilidades às pessoas com deficiência $^{27-28}$ e/ou com a população idosa. ${ }^{8}$

\section{Sobrecarga de trabalho sobre os dirigentes}

Ademais, foi ressaltado pelos representantes da ginástica gaúcha que há uma sobrecarga de funções enfrentada pelos gestores. Essa sobrecarga, associada ao trabalho de promover uma nova modalidade esportiva em um estado tão tradicional em ginástica artística e rítmica, faz com que a modalidade acabe sendo deixada de lado. A diretora técnica salienta a dificuldade ao realizar diversas funções na federação, o que a sobrecarrega e torna impossível gerenciar tantas tarefas em conjunto: "O comitê técnico sou eu, que também sou diretora técnica da GA. É no amor né, não tem remuneração, não consigo dar conta de muitas coisas então eu foquei o GPT só no final do ano." A acumulação de cargos em federações também foi detectada em outros trabalhos de gestão na ginástica, o que indica fato recorrente nessa área., 29

O Código Civil de $2001^{40}$ não permite que as associações tenham fins lucrativos e, por estarem nessa condição, as federações enfrentam essa realidade, sendo seus dirigentes pessoas jurídicas de direito privado. Referente a isso, Mazzei e Bastos ${ }^{30}$ explicam que as legislações existentes não especificam claramente o papel das Federações no desenvolvimento do esporte brasileiro e que, provavelmente por esse motivo, os dirigentes ainda possuem um perfil amador e não capacitado em áreas de gestão do esporte.

Soma-se a isso o fato de que a gestão no esporte implica em inúmeras habilidades e competências e, no Brasil, ainda são recentes os cursos de graduação e/ou pós-graduação que

\begin{tabular}{|l|l|l|l|l|l|l}
\hline (C) Conexões & Campinas, SP & v. 14 & n. 4 & p. 25-46 & out./dez. 2016 & ISSN 1983-9030
\end{tabular}


tratam sobre essa especificidade, característica que faz com que o conhecimento adquirido e colocado em prática pelo gestor seja decorrente e construído pela e durante a própria atuação. ${ }^{30-31}$ Ainda,

Verifica-se então que no campo da formação do profissional para atuar na área, ações têm sido desenvolvidas, mas a simples frequência de 'administradores esportivos' em cursos que repassem e discutam superficialmente os conceitos básicos da área não será suficiente para a almejada mudança e a credibilidade da área no país. ${ }^{32: 296-297}$

Parece que a capacitação dos gestores não acompanhou as demandas previstas para o cargo em questão. Segundo Tassinari ${ }^{33}$ as organizações e/ou federações esportivas devem manter harmonicamente os aspectos técnicos, políticos e administrativos. Ao se integrar à mídia, patrocínio e profissionalismo o esporte passou a estabelecer novas relações entre atletas, treinadores, médicos, patrocinadores, dirigentes, árbitro, público e políticas públicas ${ }^{1}$. Observa-se, então, que o esporte tem caminhado para as perspectivas do mundo do trabalho e economia.

Portanto, fica claro que o gestor deve conciliar políticas, definir missão, dominar aspectos administrativos, utilizar do marketing, imagem e comunicação, liderar com qualidade, ${ }^{34-35}$ porém sem perder de vista a manutenção e preservação da ética esportiva, regras da modalidade, dentre outros.

Visto essas demandas, Meira, Bastos e Bohme ${ }^{36: 257}$ indicaram que o COB disponibilizou, por duas vezes, o "Curso Avançado de Gestão Esportiva" com o objetivo de capacitar profissionais das Confederações Brasileiras Olímpicas em gestão de organizações esportivas olímpicas, estratégica, de recursos humanos, financeira e de organização de grandes eventos. No ano de 2010, o Comitê Olímpico Brasileiro"1 (COB) também ofereceu o "Curso Fundamentos da Administração Esportiva" (FAE), voltado para os "representantes do COB, do Comitê Paraolímpico Brasileiro (CPB) e das Confederações, dos três níveis do governo, de atletas e ex-atletas olímpicos e pan-americanos, de clubes e de instituições esportivas ligadas ao Movimento Olímpico."

O presidente mostrou-se aberto ao trabalho da GPT, mas indica que tem "tentado encontrar alguém que se interesse para trabalhar com essa modalidade e até aí pouco se desenvolve, 
poucos são os que se envolvem com a modalidade. Geralmente o pessoal aqui do Sul está familiarizado com a ginástica de competição".

É possível notar uma prevalência dos dirigentes a darem uma maior ênfase às suas ginásticas de origem. A GA é a modalidade que mais recebe incentivos e é a melhor desenvolvida no estado, isso se deve parte a história da modalidade e cultura local, mas também está ligada ao comodismo, uma vez que é mais fácil trabalhar com um esporte já estabelecido e conhecido.

\section{A INFLUÊNCIA DE GINÁSTICA ARTÍSTICA E GINÁSTICA RÍTMICA DE ALTO RENDIMENTO NO CENÁRIO CULTURAL GAÚCHO}

As ginásticas artística e rítmica são as de maior relevância no estado do Rio Grande Sul. Parte disso associa-se à tradição criada por trás das mesmas, com o surgimento de grandes nomes da ginástica brasileiras advindos de clubes como o Grêmio Náutico União. A ginástica rítmica surgiu no estado em 1972 e, mais tarde, com a criação do Grupo de Ginástica da Escola de Educação Física do Instituto de Porto Alegre, que iniciou a prática desta modalidade. ${ }^{37}$

Esse grupo utilizava, além dos aparelhos comuns da GR (corda, arco, bola, maças e fita), instrumentos regionais como pandeiros, tamboretes, lenços coloridos e faixas largas, acompanhados musicalmente do piano. Também em 1972, realizou-se o Curso de Extensão de Ginástica Feminina Moderna na Escola Superior de Educação Física da Universidade Federal do Rio Grande do Sul - ESEF-UFRGS, ministrado por Ilona Peuker. Em 1973, a Ginástica Feminina Moderna foi incorporada ao currículo do curso de Educação Física do Instituto de Porto Alegre. ${ }^{37}$

Na GR, as gaúchas se fizeram presentes em Campeonatos Mundiais, Pan-Americanos e Copa 4 Continentes desde 1990. O Campeonato Mundial em Atenas- Grécia, de 1991 contava com uma seleção brasileira bastante significativa, composta por técnicas e ginastas gaúchas. Já em 1992 a gaúcha Marta Cristina Schonhorst, que teve seu trabalho de base desenvolvido no RS e, posteriormente tendo treinado em São Paulo, participou dos Jogos Olímpicos de Barcelona. 
A ginástica artística no Rio Grande do Sul possui uma raiz cultural muito forte, uma vez que a ginástica olímpica brasileira teve seu início nesse estado, com Johann Friedrich Ludwig Jahn, precursor da ginástica no século XIX. Em 1867, surgia em Porto Alegre a Sociedade de Ginástica de Porto Alegre, conhecida atualmente como SOGIPA, mas somente em 1950 foi realizado o primeiro torneio nacional reunindo atletas gaúchos, cariocas e paulistas. ${ }^{7}$

Considerado um "celeiro" de grandes ginastas, o Grêmio Náutico União (GNU) teve sua iniciação em 1950. Dentro de seus ginásios nasceram nomes internacionalmente conhecidos da GA, como Daiane dos Santos e Mosiah Rodrigues. A sensação e maravilha que foi a atleta Daiane dos Santos fez com que a promoção da prática da ginástica artística fosse incentivada, tanto por clubes e federação gaúcha quanto pelos meios midiáticos. ${ }^{38}$

Acredita-se que este cenário se dá devido à cultura local e falta de incentivos político-sociais. A cultura gaúcha possui grande tradição, tanto em GA quanto em GR, na formação de atletas de alto nível, o que faz com que as demais modalidades sejam deixadas de lado e encontrem grandes dificuldades para serem inseridas culturalmente. Ainda segundo João Oliva, quando perguntado se este fato ocorre associado à falta de conhecimento ou devido à cultura: “Cultural mesmo, a ginástica é a de competição, o governo faz uma coisa que hoje é a olimpíada, então o enfoque é a ginástica de competição, mas o que falta é link paralelo”.

É importante salientar que o Ministério do Esporte é responsável pela construção da Política Nacional de Esporte que, para além do alto rendimento, deve promover ações de inclusão social e garantir à população brasileira o acesso gratuito à prática esportiva, qualidade de vida e desenvolvimento humano ${ }^{39}$. A modalidade GPT, se encaixaria nesta premissa. Porém, o que observamos é uma relação mais clara da arrecadação nacional em prol dos esportes olímpicos. É repassado ao Comitê Olímpico Brasileiro $85 \%$ de $2 \%$ da arrecadação bruta das loterias federais. ${ }^{40}$ Por sua vez, aquela entidade repassa $36 \%$ do total a 29 confederações responsáveis por modalidades presentes no programa dos Jogos Olímpicos, baseada nos seguintes critérios:

a) Nível Técnico;

b) Probabilidade e posterior confirmação de classificação entre os finalistas;

c) Número de Praticantes da modalidade inscritos ou registrados oficialmente; 
d) Número de Federações filiadas às Confederações;

e) Infraestrutura Técnica e Administrativa para o Desenvolvimento da Modalidade;

f) Aquisição de Material e Equipamento para o Desenvolvimento da Modalidade; e

g) Resultado do Diagnóstico e Análise das Modalidades Olímpicas. ${ }^{41}$

Pois bem, a GPT não adentra no item das modalidades olímpicas, mas cremos na sua significativa contribuição nos itens c, d e f. Ora, por meio dos fundamentos da ginástica, preconizado pela GPT, pode-se ampliar o nível formativo que, por sua vez, poderá ampliar os talentos nas diferentes modalidades ginásticas - pelas possibilidades reais de intervenção nos diferentes setores da sociedade, podemos ampliar e consolidar as federações ginásticas nos estados faltantes e, pelas parcerias com outras secretarias (que não apenas a esportiva), como já citamos anteriormente, melhorar a política de aquisição de equipamentos (que não apenas oficiais de competição, mas de trato pedagógico e que melhorem o processo ensinoaprendizagem).

Por fim, o referido "link paralelo" citado pelo presidente diz respeito à introdução da GPT no âmbito escolar (em todos os níveis) e também à inclusão social de pessoas com deficiência. Ainda não há nenhum tipo de conhecimento por parte de professores de escolas públicas e privadas sobre a modalidade, tornando nula a participação e integração deste público. Ainda na UFRGS existe a possibilidade de inserção de pessoas com deficiência nos projetos de extensão de ginásticas, mas a grande maioria da população acaba por procurar somente a GA, uma vez que não conhecem a outra modalidade.

\section{PERSPECTIVAS}

\section{Fortalecer o festival gaúcho de ginástica geral}

A Federação Rio-Grandense de Ginástica realiza, há três anos, um evento anual de ginástica geral que busca trazer elementos da GPT. O Festival de Ginástica Geral tem como itens obrigatórios: "as apresentações dos grupos participantes devem refletir o vasto domínio da GPT, dentro de toda a sua diversidade e apresentar ao menos 3 formações básicas." ${ }^{42}$ Ainda ocorre a premiação da instituição com o maior número de participantes e da instituição com melhor desempenho artístico.

\begin{tabular}{l|l|l|l|l|l|l}
\hline (C) Conexões & Campinas, SP & v. 14 & n. 4 & p. 25-46 & out./dez. 2016 & ISSN 1983-9030 \\
\hline
\end{tabular}


Dentro do regulamento do Festival promovido pela federação estão as seguintes exigências: ${ }^{42}$

- As apresentações dos grupos participantes deverão refletir o vasto domínio da Ginástica para Todos, dentro de toda a sua diversidade;

- Apresentando ao menos 3 (três) formações básicas: (linha, circulo, quadrado, triângulos, losangos, pirâmides, entre outras)

- As coreografias a serem apresentadas no Gym Sul e Festivais de GPT poderão ser executadas por ginastas de ambos os sexos, simultaneamente ou separadamente;

- As coreografias poderão ser realizadas a mãos livres ou utilizando qualquer tipo de material, sempre procurando formas originais de expressão.

Buscando incentivar a participação de um maior número de pessoas no evento esportivo, a Federação gaúcha estabeleceu os seguintes critérios para a premiação ${ }^{42}$

- Todos os participantes serão premiados com medalhas de participação;

- Serão premiadas com troféu:

a. A instituição com o maior número de participantes;

b. A instituição com melhor desempenho artístico;

c. A instituição que apresentar melhor desempenho artístico em: Coreografia, figurino, música e ritmo através de uma comissão de três membros convidados pela Federação, que fará uma avaliação subjetiva da seguinte maneira: 1 a 5 em cada quesito, totalizando o máximo de 20 pontos. Por fim, para critério de desempate será levado em conta:

1- Maior número de participantes;

2- Representante mais velho;

3- Representante mais novo.

Ao serem questionados sobre o cenário atual da GPT no Rio Grande Sul, os dirigentes citaram o festival anual como forma ativa desta modalidade. Para a diretora técnica Márcia Leite, o festival de 2015 foi bastante expressivo e contou com aproximadamente 130 crianças, um número alto e que não era esperado pela federação. $\mathrm{O}$ presidente da federação João Oliva ressalta que várias entidades compareceram: “(...)7 entidades diferentes (de 28 entidades convidadas) e esse é o nosso ginástica para todos, é uma forma de festival, eles 
fazem uma apresentação valorizando dificuldade numérica; de exercício e pontuação, de coreografia e de vestimentas. Esse ai é o nosso GPT."

A falta de conhecimento, incentivo e medo de uma nova modalidade são os principais fatores que impedem o crescimento desta ginástica no estado. Ao ser perguntado sobre a prática da GPT em clubes e associações esportivas, o presidente João Oliva comenta sobre a força das ginásticas artística e rítmica de alto rendimento, que são tradicionais nos clubes e, por isso, temem que a chegada de novas modalidades possa acarretar na perda de verbas, espaço físico e estrutura: “(..)existe um tabu e um medo que essas ginásticas que estão vindo possam travar ou concorrer com eles, então eles não querem. (...)”.

Consolidar o festival parece ser um caminho propício ao desenvolvimento da GPT, uma vez que os festivais são uma das manifestações mais importantes da modalidade. ${ }^{29}$ No entanto é preciso ampliar a visão e organização das aulas. Se o festival consolidar experiências dos fundamentos e momentos democráticos e colaborativos de aula apenas para atender ao evento, parece que a função da GPT ficará deturpada.

Porém, se a intenção da consolidação e ampliação do festival for o congraçamento efetivo dos locais de prática de ginástica no RS, aproximação entre a federação e ambientes propício da massificação e indicação de aulas em que os fundamentos estejam presentes de forma lúdica, formativa, então vemos uma perspectiva futura.

\section{A GINÁSTICA NAS UNIVERSIDADES E ESCOLAS DO ENSINO BÁSICO}

Apesar das dificuldades encontradas, existe ainda uma tentativa recente de introduzir a GPT nas universidades de forma que os acadêmicos e futuros profissionais conheçam e se interessem pelo esporte. Para o presidente da federação, o caminho para desenvolver a GPT no estado é união das universidades e a formação e conhecimento dos acadêmicos na área: “(...)juntando a UFRGS (Universidade Federal do Rio Grande do Sul) e UCS (Universidade de Caxias do Sul), vamos tentar fazer o modelo que já existe no país, que é o caminho da universidade e projetos institucionais, para ver se desencanta $e$ um dia vira performance(...)”. 
Ainda sobre a ginástica dentro das universidades, foi questionado sobre o comportamento dos acadêmicos com relação à modalidade, uma vez que o presidente também é professor da UFRGS: “(...) eu já estou dentro da universidade há 15 anos, desse grupo bolsistas de extensão) nesses 15 anos só 2 estão trabalhando com ginástica de competição. "

A falta de interesse e participação dos acadêmicos é muito preocupante. Para o pleno desenvolvimento e crescimento de qualquer modalidade esportiva é necessária a renovação dos responsáveis pela mesma, assim se os acadêmicos não buscam interagir, pesquisar ou conhecer estas modalidades, estas demoram a crescer ou até mesmo não se desenvolvem. Este é o caso da GPT no estado, por ser pouco desenvolvida nos currículos acadêmicos das principais universidades gaúchas, acaba sendo ignorada pelos docentes e dessa forma não se faz conhecer aos acadêmicos.

A ausência de eventos que auxiliem na divulgação da modalidade também é responsável pelo pouco conhecimento acadêmico. O calendário competitivo tanto da GA quanto da GR é extremamente abarrotado de eventos e competições todos os meses do ano, e por esse motivo se fazem presentes a todo o momento, despertando o interesse e a curiosidade dos estudantes. Já a GPT está restrita a um único evento, que acontece após o final do ano letivo, não sendo divulgada fora dos clubes e associações esportivas que fazem parte do circuito competitivo de GA e GR.

Os acadêmicos gaúchos possuem pouquíssimas oportunidades de conhecerem a modalidade. Dessa maneira, o crescimento da mesma fica restrita e lenta, uma vez que não possui incentivadores e conhecedores do tema que possam contribuir para o seu pleno desenvolvimento fora das universidades mais tarde.

Por este motivo e pensando em políticas de incentivo que possam auxiliar na introdução efetiva da GPT, os representantes da ginástica gaúcha sugerem a realização de fóruns e clínicas da modalidade de forma a incentivar, renovar e (re)conhecer a mesma, o que está em consonância com o desenvolvimento da GPT em outros estados e mesmo no país. ${ }^{43}$

A UFRGS e a UCS já possuem um grupo de pesquisa em ginásticas que interliga estas instituições de forma a ampliar o conhecimento científico. Acredita-se que esta seja uma das

\begin{tabular}{l|l|l|l|l|l|l}
\hline (C) Conexões & Campinas, SP & v. 14 & n. 4 & p. 25-46 & out./dez. 2016 & ISSN 1983-9030
\end{tabular}


maneiras para levar ao conhecimento dos acadêmicos um pouco mais sobre a GPT, de forma que possam auxiliar em seu pleno desenvolvimento.

O envolvimento de escolas com a modalidade também está sendo pensado. É considerado importante o envolvimento escolar com a GPT com a finalidade de mostrar que é uma atividade de baixo custo, não necessita de muitos materiais e é de fácil de desenvolvimento. Assim, seria possível iniciar atividades de GPT em colégios e instituições que possuem os recursos financeiros para adquirir o material que a GA e a GR precisam.

\section{CONSIDERAÇÕES FINAIS}

Os discursos confirmam que, apesar da abertura para consolidar e ampliar as ações na modalidade de GPT no RS, não há um planejamento estratégico a curto, médio e longo prazo, principalmente devido às demandas de outras modalidades e à sobrecarga de trabalho dos gestores.

A gestão nos meios esportivos brasileiros precisa conjugar elementos usuais das estruturas empresariais, caso contrário, está fadado à inércia. As novas dinâmicas organizacionais exigem prestação de serviços conectados com as leis de mercado. Captar recursos financeiros, realizar prestação de contas, organizar eventos em diferentes níveis, negociar espaços de infraestrutura e, por vezes, lidar com a mídia jornalística e televisiva são alguns dos requisitos dos envolvidos nas federações.

É interessante notar que houve uma preocupação dos gestores em, não apenas lamentar casos, mas o de demonstrar interesse em apontar caminhos que precisam ser traçados. Inclusive, após a pesquisa, a primeira autora do trabalho foi convidada a integrar a direção do Comitê Técnico de Ginástica para Todos do Rio Grande do Sul, com a missão de unir força em prol do desenvolvimento da GPT no estado, demonstrando que para mudarmos realidades, é preciso, antes de criticar, agir!

\section{NOTAS}

${ }^{1}$ Interessante notar que a federação ainda mantém o Festival com o nome de "Ginástica Geral”. Desde 2007 a FIG oficializou a modalidade para “Ginástica Para Todos" 20. 


\section{REFERÊNCIAS}

${ }^{1}$ COSTA, Christian Pinheiro da. Estudo sobre modelos de desenvolvimento de federações desportivas no estado do Pará - Brasil. 2010. Tese (Doutorado) - Faculdade de Desporto, Universidade do Porto, Porto, 2010.

${ }^{2}$ HELENO, G. Gestão esportiva. Revista Brasileira de Administração, Brasília, mar./abr. 2010.

${ }^{3}$ DACOSTA, Lamartine Pereira (Org.). Atlas do esporte do Brasil. Brasília: CONFEF, 2005.

${ }^{4}$ FIGUEIROA, Laís Stroesser; MAZZEI, Leandro; BASTOS, Flávia Cunha. Gestão da Confederação Brasileira de Ginástica Estética de Grupo: um estudo de caso. Revista Portuguesa de Ciências do Desporto, Porto, v. 14, p. 471-483, 2014.

${ }^{5}$ DE BOSSCHER, Veerle et al. The global sporting arms race: an international comparative study on sports policy factors leading to international sporting success. Oxford: Meyer \& Meyer Sport, 2008.

${ }^{6}$ DE BOSSCHER, Veerle; DE KBOP, P.; HEYNDELS, B. Comparing relative sporting success among countries: create equal opportunities in sport. Journal for Comparative Physical Education and Sport, Schorndorf, v. 3, n. 3, p. 49-69, 2003.

${ }^{7}$ CONFEDERAÇÃO BRASILEIRA DE GINÁSTICA (CBG). Estatuto da Confederação Brasileira de Ginástica. Disponível em: 〈http://www.cbginastica.com.br/estatuto >. Acesso em: 07 abr. 2016.

${ }^{8}$ SIMÕES, Regina et al. A produção acadêmica sobre ginástica: estado da arte dos artigos científicos. Revista Brasileira de Educação Física e Esporte, São Paulo, v. 30, n. 1, p. 183198, 2016.

${ }^{9}$ BARDIN, Laurence. Análise de conteúdo. Lisboa: Edições 70, 2010. 
${ }^{10}$ ROCHA, Claudio Miranda da; BASTOS, Flávia da Cunha. Gestão do esporte: definindo a área. Revista Brasileira de Educação Física e Esporte, São Paulo, v. esp., n. 25, p. 91-103, 2011 .

${ }^{11}$ BASTOS, Flavia da Cunha; MAZZEI, Leandro C.; SARMENTO, J. P. Analysis of Brazilian sports management congresses abstracts from 2005 to 2009. In: EUROPEAN CONGRESS OF SPORT MANAGEMENT, 19., 2011, Madrid. Abstracts... Madrid: European Association for Sport Management, 2011.

${ }^{12}$ AMARAL, Cacilda Mendes dos Santos; BASTOS, Flávia da Cunha. O gestor esportivo no Brasil: revisão de publicações no país. Revista Intercontinental de Gestão Desportiva, Rio de Janeiro, v. 5, n. 1, p. 68-78. 2015.

${ }^{13}$ CHELLADURAI, Packianathan. Sport management: defining the field. European Journal for Sport Management, Groningen, v.1, n.1 p.7-21, 1994.

${ }^{14}$ CHALIP, Laurence Hilmond. Towards social leverage of sport events. Journal of Sport \& Tourism, Abingdon, v. 11, n. 2, p. 1-19. 2006.

${ }^{15}$ PITTS, Brenda G. Sport management at the millennium: a defining moment. Journal of Sport Management, Groningen, v.15, n.1, p. 1-9. 2001.

${ }^{16}$ HOULIHAN, Barrie.; GREEN, Mike. Comparative elite sport development: systems, structures and public policy. Burlington: Elsevier, 2008.

${ }^{17}$ DE BOSSCHER, Veerle. et al. Explaining international sporting success: an international comparison of elite sport systems and policies in six countries. Sport Management Review, Sydney, v.12, p.113-136, 2009.

${ }^{18}$ PAOLIELLO, Elizabete. Ginástica geral: experiências e reflexões. São Paulo: Phorte, 2008 . 
${ }^{19}$ CARBINATTO, Michele Viviene. Ginástica para Todos na escola. In: SIMOES, Regina; BERTUCCI, J.; MOREIRA, Wagner Wey (Org.). Escola de tempo integral: linguagens e expressões. Uberaba: Ed. da UFTM, 2014. v. 1, p. 23-33.

${ }^{20}$ TOLEDO, Eliana de; TSUKAMOTO, M.; CARBINATTO, Michele Viviene Fundamentos da Ginástica Para Todos. In: NUNOMURA, Myrian. (Org.). Fundamentos da ginástica. 2ed. Jundiaí: Fontoura, 2016. p. 12-40.

${ }^{21}$ SANTOS, José Carlos Eustáquio. Ginástica geral: elaboração de coreografias, organização de festivais. Jundiaí, SP: Fontoura, 2001.

${ }^{22}$ BRATIFISCHE, S. A.; CARBINATTO, Michele Viviene. Inovação e criação de materiais: em busca da originalidade na ginástica para todos. In: MIRANDA, R. C. F.; EHRENBERG, M. C.; BRATIFISCHE, S. (Org.). Temas emergentes de pesquisa em ginástica para todos. Jundiaí: Fontoura, 2016.

${ }^{23}$ VELARDI, Marília; NISTA-PICCOLO, Vilma Leni. Ginástica geral: coletânea: textos e sínteses do I e II Encontro de Ginástica Geral. Campinas: UNICAMP, 1996.

${ }^{24}$ OLIVEIRA, N. R. C. Ginástica para todos: perspectivas do contexto no lazer. São Paulo. Revista Mackenzie de Educação Física e Esporte, v. 6, n. 1, p. 27-35, maio 2007.

${ }^{25}$ PROGRAMA SEGUNDO TEMPO. 2016. Disponível em: <http://portal.esporte.gov.br/snee/segundotempo>. Acesso em: 15 maio 2016.

${ }^{26}$ CARBINATTO, Michele Viviene; BORTOLETO, Marco Antônio Coelho. Ginástica para Todos: princípios para a prática. In: SILVA, JWP; GONÇALVES-SILVA, L.L; MOREIRA, Wagner Wey. Educação Física e seus diversos olhares. Mato Grosso do Sul: Ed. da UFMS, 2016.

${ }^{27}$ BLUMENAU. Prefeitura Municipal. Disponível em:

<http://www.blumenau.sc.gov.br/secretarias/secretaria-de-educacao/semed/nova-modalidadedo-paradesporto-escolar-inicia-nesta-quarta-feira82 >. Acesso em: 12 maio 2016.

\begin{tabular}{|l|l|l|l|l|l|l|}
\hline CCConexões & Campinas, SP & v. 14 & n. 4 & p. 25-46 & out./dez. 2016 & ISSN 1983-9030
\end{tabular}


${ }^{28}$ SPECIAL OLYMPICS. 2016. Disponível em: http://specialolympics.org.br/ . Acesso em: 15 maio 2016.

${ }^{29}$ PATRICIO, Tamiris L.; CARBINATTO, Michele Viviene; BORTOLETO, Marco Antônio Coelho. Festivais de ginástica no mundo e no Brasil: reflexões gerais. Revista Brasileira de Educação Física e Esporte, São Paulo, v. 30, n. 1, p. 199-216, 2016.

${ }^{30}$ MAZZEI, Leandro Carlos et al. Gestão da Confederação Brasileira de Judô: um estudo de caso. Revista Intercontinental de Gestão Desportiva, v. 2, n. 1, p. 30-42. 2012

${ }^{31}$ MAZZEI, Leandro Carlos; BASTOS, Flávia da Cunha. Gestão do esporte no Brasil: desafios e perspectivas. São Paulo: Ícone, 2012.

${ }^{32}$ BASTOS, Flávia da Cunha. Administração esportiva: área de estudo, pesquisa e perspectivas no Brasil. Motrivivência, Florianópolis, v. 20-21, n. 15, p. 295-306. 2003.

${ }^{33}$ TASSINARI, L. Gestão esportiva: uma abordagem sobre a disposição e a contextualização das organizações esportivas. http://www.uniritter.edu.br/w2/letras/palavora_anterior/arquivos/15\%20\%20Artigo\%20Loren zo.pdf. 2007.

${ }^{34}$ CELMA, Joan. ABC del gestor deportivo. Zaragoza: INDE, 2004.

${ }^{35}$ CASCA, Dani Garcia. Perspectivas de la gestión deportiva municipal y de modelos de gestión. In: CONGRESSO DE GESTIÓN DEPORTIVA DE CATALUÑA. 2000. Anais... Zaragoza, 2000.

${ }^{36}$ MEIRA, Tatiana de Barros; BASTOS, Flávia da Cunha; BÖHME, Maria Tereza Silveira. Análise da estrutura organizacional do esporte de rendimento no Brasil: um estudo preliminar. Revista Brasileira de Educação Física e Esporte, São Paulo, v. 26, n. 2, p. 251262, p. 51-63. 2012. 
${ }^{37}$ MÜHLEN, Johanna Coelho von; NATIVIDADE, Daniela; GOELLNER, Silvana Vilodre. Fragmentos da história da ginástica rítmica no Rio Grande do Sul: as primeiras professoras e suas memórias. Pensar a Prática, Goiânia, v. 16, n. 1, p. 101-117. 2013.

${ }^{38}$ MELLO, Vanessa Scalei de. Daiane dos Santos, a gauchinha de ouro: articulações entre jornalismo esportivo e identidade gaúcha. 2007. Dissertação (Mestrado) - Universidade Federal do Rio Grande do Sul, Porto Alegre, 2007.

${ }^{39}$ BRASIL. Ministério do Esporte. O Ministério. Disponível em: <http://portal.esporte.gov.br/>. Acesso em: 20 jan. 2010.

${ }^{40}$ BRASIL. Ministério do Esporte. Lei no 10.264, de 16 de julho de 2001, acrescenta inciso e parágrafos ao art. 56 da Lei n. 9.615, de 24 de março de 1998, que institui normas gerais sobre desporto. Disponível em: <http://www.planalto.gov.br/ccivil_03/Leis/ LEIS_2001/L10264.htm>. Acesso em: 14 abr. 2016.

${ }^{41}$ COMITÊ OLÍMPICO BRASILEIRO (COB). Demonstração da aplicação dos recursos provenientes da Lei Agnelo- Piva 2009. Disponível em: <http://www.cob.org.br>. Acesso em: 15 maio 2010.

${ }^{42}$ LEITE, M. Regulamento técnico de ginástica para todos. Federação Rio-Grandense de Ginástica, 2015.

${ }^{43}$ CARBINATTO, Michele Viviene; SOARES, Daniela Bento; BORTOLETO, Marco Antônio Coelho. GYM Brasil: Festival Nacional de Ginástica Para Todos. Motrivivência, Florianópolis, v. 28, n. 49, p. 128-145, 2016. 